\title{
Minimum prices and social interactions: Evidence from the German renewable energy program
}

\author{
Justus Inhoffen* \\ VU Amsterdam \& DIW Berlin
}

\author{
Christoph Siemroth ${ }^{\dagger}$ \\ University of Essex
}

\author{
Philipp Zahn \\ University of St. Gallen
}

November 13, 2018

\begin{abstract}
Minimum prices above the competitive level can lead to allocative inefficiencies. We investigate whether this effect is more pronounced when decision makers are influenced by their social environment. Using data of minimum prices for renewable energy production in Germany, we test if individual decisions to install photovoltaic systems are affected by the investment decisions of others in the area. We implement a propensity score matching routine on municipality level and estimate that existing panels in the municipality increase the probability and number of further installations considerably, even in areas with minimal solar radiation. Thus, social interaction can add secondary inefficiencies to the known allocative problems of minimum prices. The social interaction effect is stronger in areas with more solar radiation and less unemployment. A larger number of existing systems and more concentrated installations increase the social effect further.
\end{abstract}

Keywords: Feed-in Tariffs, Neighborhood Effects, Peer Effects, PV Systems, Renewable Energy, Solar Energy, Subsidies

JEL Classification: H23, L14, Q42, Q48, Q58

*Address: VU Amsterdam, De Boelelaan 1105, 1081 HV Amsterdam, Netherlands. Email: j.h.inhoffen@vu.nl

†Address: University of Essex, Wivenhoe Park, CO4 3SQ Colchester, United Kingdom. Email: christoph.siemroth@essex.ac.uk

${ }^{\ddagger}$ Corresponding author, Address: University of St. Gallen, Varnebueelstr. 19, 9000 St. Gallen, Switzerland. Email: philipp.zahn@unisg.ch 


\section{Introduction}

Failing to include network structure can lead one to a deficient understanding of an observed behavior and can lead to poor policy design. - Jackson (2016, p. 1)

The effect of social interaction with family, friends, or neighbors on economic decisions has been documented in many settings. However, neither empirical evidence nor theoretical insights about these social interaction effects are typically considered in the design of new policies, even if policy success depends on the effect of social interaction.

In this paper, we investigate the consequences of ignoring social interaction for one particular policy instrument: minimum prices. It is well known that minimum prices above market rates can lead to distorted incentives and production decisions. We ask whether this primary inefficiency can be amplified in the presence of social interaction or neighborhood effects because others join in the inefficient decisions of the first-movers. We study this question for minimum prices (also called feed-in tariffs) of a large government program in Germany with the goal of expanding private photovoltaic (PV) system installations.

In the solar energy context, the inefficiency refers to the spatial allocation of PV installations. If a social planner aims to maximize solar energy production for a given budget, or minimize costs for a given (expected) solar energy output, then the efficient spatial allocation is to install PV systems only in areas with high solar radiation. This is because the same PV system (same cost) produces more energy in these areas. High feed-in tariffs typically do not achieve this efficient spatial allocation, because it pays to install PV systems even in areas with low solar radiation.

Our main result is that the number of PV installations were increased due to social interaction - even in northern areas with minimal solar potential. Thus, social interaction appears to be a cause of an inefficient spatial allocation and exacerbate the known allocative deficiencies of minimum prices. While our findings do not question subsidies for renewable energy in general, they do suggest that funds could be used more efficiently because PV systems are not installed in areas where they could produce the most energy.

The program we study is one of the largest renewable energy subsidy schemes in the world, the German renewable energy act (Erneuerbare Energien Gesetz, EEG). With the EEG, the share of green energy in Germany increased from 6\% to $32 \%$ within 15 years (BMWi, 2016); it is estimated that around 27.7 billion EUR will be spent in 2018 alone on feed-in tariffs (BMWi, 2017). The EEG regulation guaranteed (i) a fixed compensation rate over 20 years for every kWh of solar energy produced (feed-in tariff), which was set above competitive market prices, and (ii) required energy network operators to feed in green energy independent of time, location, demand, supply, and energy prices. The EEG regulation is ideal to test for the effect of social interaction in a policy context because it is very simple and - unlike in markets - the decision whether to claim the feed-in tariffs and to install a 
generator does not depend on (the expectations of) the actions of other agents. We use the complete EEG data from year 2000, which is early in the PV systems adoption curve, to 2012. The vast majority of our observations are residential PV systems mounted on roofs, with a small minority mounted on ground structures.

To estimate the effect of social interaction, we employ a propensity matching procedure based on rich data on the municipality level. ${ }^{1}$ When the EEG legislation started, every municipality was untreated - nobody could be influenced by someone else who has a PV system supported by the EEG. The first PV installation under the EEG in a municipality changed this status; starting with the first installation, others may be influenced by the presence of PV installations. For example, neighbors may talk to each other and convince the non-adopters to get a system as well. Or households in the same municipality may seek to copy the behavior of their friends for status reasons. We use the terms social interaction or social effect, because the effect on others is more general than mere peer effects, which are usually expected to work through personal interaction. Here, personal interaction may not be necessary to affect others; the high visibility of a PV system may be enough to influence the neighborhood. While we cannot distinguish the different channels of social effects in our aggregate data analysis, we can determine whether they exist and quantify them.

Whenever a municipality is treated, i.e., the first PV system is installed, we match it with a municipality where no system is installed and which is comparable in size, number of inhabitants, solar radiation, income, voting history etc. The difference of the probability whether at least one more system is installed over the next year between these treatment and control municipalities captures the effect due to social interaction, i.e., the effect due to a system already being present in the area.

According to our estimates, the effect of social interaction is large and increases the probability of PV installations by about $25 \%$ (from a base rate of about $50 \%$ ) and the number of PV installations by about $50 \%$ (from a base rate of about 1.6 installations). These estimates increase with more installations in the area. Hence, we provide evidence that neighbors or other households in the same municipality influence peers in the decision to install a PV system and use the EEG public support scheme. We also find that social interaction has a stronger effect in municipalities with more solar radiation and less unemployment, and increases with the number of existing installations in the area. This social effect is positive even in areas with minimal solar radiation, which suggests that social interaction can exacerbate an existing allocative inefficiency.

Since the primary inefficiency is due to the non-competitive policy design, a new policy can potentially improve both the primary and secondary inefficiency. In our policy implications, we therefore argue that a competitive allocation system such as auctions could be an

\footnotetext{
${ }^{1}$ In our choice of the level of spatial aggregation, we faced a trade-off between more observations with a finer level of aggregation and considerably better data on local socio-economic conditions with a coarser level of aggregation. Since most of the variables that affect the PV installation decisions are not available on a finer geographical level, we conduct the analysis on the finest level possible, i.e., the municipality level.
} 
improvement. And indeed, this is the direction of the latest changes to the EEG.

\subsection{Related Literature}

Social interaction has long been known to affect individual behavior (e.g., Becker and Murphy, 2000). In the presence of social interaction, the effectiveness of policy interventions may change. Interestingly, the EEG is not so much a policy given existing social effects, but social effects are a consequence of the policy itself. Thus, it is crucial to recognize the effects of social interaction when designing the policy. In the context of power production, where social interaction may lead to a spatially inefficient allocation, this side-effect of policy is particularly important. Note also that we are interested in the aggregate effect and not in individual elasticities. Thus, the identification problems from the "social multipliers" literature (Glaeser et al., 2003) are not an issue here.

Our paper is related to the interdisciplinary literature on innovation adoption. Evidence suggests that clustering of innovation adopters occur regularly-often due to social learning (Young, 2009). This link has also been made for the adoption of photovoltaic panels (Bollinger and Gillingham, 2012; Richter, 2014). Several papers use spatial methods to investigate patterns and show that photovoltaic panels tend to be clustered (Graziano and Gillingham, 2015; Rode and Weber, 2016). While the focus of almost all of these papers is the better understanding of peer effects in PV adoption, we are more interested in (renewable energy) policy and how its success is affected by social interaction.

Rode and Weber (2016) investigate peer effects also with EEG PV systems data. They estimate a spatial diffusion model from epidemiology, which models adoption of a new technology (PV panels) as a function of the adoption rate in the surrounding area. Rode and Weber (2016) conclude that adoption choices are affected by others, and that this influence quickly diminishes with distance. Rode and Müller (2016) pursue a panel data approach and find that peer effects weaken over time and are stronger in eastern Germany. We also find that the strength of social effects diminishes during the early years of the regulation, but find that this change is attributable to sunnier municipalities adopting first.

In contrast to Rode and Weber (2016) and Rode and Müller (2016), we construct an explicit control group to obtain the counterfactual outcomes and estimate the social effects. Moreover, our matching approach explicitly imposes a common support and therefore ensures that the results are not driven by interpolation which is sensitive to the functional form (e.g., Blundell and Dias, 2009), but direct comparison of similar units.

From a policy perspective, our paper is related to analyses of feed-in-tariffs (cf. Couture and Gagnon (2010) for a discussion of different remuneration models). As mentioned before, the cost-effectiveness of the fixed EEG feed-in-tariffs has been questioned, see for instance Frondel et al. (2010). The tariffs for solar energy are seen as particularly critical. Our results reinforce these findings as the effectiveness of feed-in-tariffs are further weakened in 
the presence of social effects.

Our work contributes to the analysis of feed-in-tariffs from the particular angle of social interaction. We do not claim our results should be the sole basis of an evaluation as we have to set aside other dimensions in our analysis. Other important policy objectives of feedin-tariffs are the effect on overall capacity of renewable energy (Dijkgraaf et al., 2018) or innovation (Böhringer et al., 2017). Previous research also looked into political constraints which are important in the assessment of policies (Kalkuhl et al., 2013) and in the understanding of how current policies came about (Jacobsson and Lauber, 2006). Lastly, it can also be argued that feed-in-tariffs are justified by further market failures, such as insufficient adaption of new technology (Jaffe et al., 2005).

\section{Policy description and PV installation decision}

\subsection{The German Renewable Energy Act}

The German Renewable Energy Act (EEG) was adopted in 2000 with the goal of climate and environment protection. To that end the EEG aimed at increasing the share of renewable energy production (BMJ, 2000). The regulation had two main provisions. First, energy grid operators were required to provide access to producers of renewable energy and to feed in the produced electricity into the grid before any conventionally produced electricity (priority access). Second, producers of renewable energy were guaranteed a fixed payment per produced kWh (often called feed-in tariff), which was set above market prices. These feed-in tariffs were viewed as necessary to increase the share of renewable energy at the time of the enactment of the law, when most renewable energy sources could not operate economically. Since its introduction in 2000, the regulation has been overhauled several times.

In this paper, we focus on the regulation concerning solar power production. ${ }^{2}$ A schedule of feed-in tariffs is guaranteed for a fixed time period, typically 20 years, and rates decrease by a fixed amount every year. The compensation per produced $\mathrm{kWh}$ varies with characteristics of the PV system. Two main factors determine the compensation rate: the size of the system (measured by capacity in $\mathrm{kW}$ ) and installations on buildings versus installations on ground structures. In general, systems on the ground as well as larger systems receive smaller compensation rates.

Partly due to large increases in solar power production at the end of the 2000s (implying large financial obligations for the following 20 years), the feed-in tariffs have been reduced

\footnotetext{
${ }^{2}$ Solar power production encompasses different methods of energy production such as direct conversion into electricity (photovoltaic) or heating of materials to propel turbines. In this article, solar energy production refers to typically small photovoltaic solar panels mounted on roofs of buildings or a system of panels mounted on ground structures.
} 
several times by the regulator. Moreover, measures ${ }^{3}$ have been taken to prevent sudden or excessive increases in PV installations (e.g., due to large price decreases for solar panels) beginning in 2009. First, in an attempt to track future solar panel price reductions, the compensation rate for new installations is set to be reduced by a fixed proportion each year. Second, the compensation rate for new installations decreases in the overall number of installations in the previous year. Thus, a larger expansion reduces the compensation available for new installations even more. As these changes took effect in 2012 and our sample only includes observations up to the year 2012, our analysis is not affected for the bulk of observations made between 2000 and $2011 .^{4}$

\subsection{Incentives for the investment decision}

The incentives that are induced by the EEG to invest in PV systems are central to our analysis. What investment patterns should we observe over regions if agents make their decisions in isolation and if social interaction does not play a role?

Given the guaranteed compensation rates, a rational agent's investment decision depends solely on the costs to install a PV system and the return stream over time, which depends on the capacity to produce electricity at his location, which in turn is mainly determined by the solar radiation and roof size. As the subsidy per $\mathrm{kWh}$ is fixed, energy demand and supply (e.g., by other renewable energy or conventional energy plants) do not affect the compensation and therefore do not play a role in the individual investment decision.

To fix ideas, consider the simplest situation: A single investor maximizes his expected wealth and decides whether to install a PV system of a fixed size or not. Then his investment rationale can be represented in the following way:

$$
\max _{x \in\{0,1\}} x\left[\sum_{t=1}^{T=20} \delta^{t} q_{t}^{k} m_{t}^{k}-C_{i}^{k}\right]
$$

The variables have the following interpretation:

- $x \in\{0,1\}$ : Choice variable. Install the system or not.

- $C_{i}^{k}$ : Cost of installation of a PV system of size $k$ for household $i$.

${ }^{3}$ Cf. https://www.clearingstelle-eeg.de/eeg2009 for the 2009, 2010, and 2011 amendments of the EEG; in German; accessed 15/09/16.

${ }^{4}$ There have been further overhauls of the regulation not affecting our data. One important change regarding the incentive structure was introduced in the amendment of 2014. Instead of a fixed compensation rate, the overall compensation for a plant should be determined by competitive procurement procedures rather than fixed feed-in tariffs. So far this is change limited to PV systems mounted on ground structures, but is set to be extended to roof-mounted systems and other energy sources in the future. See http: //www.erneuerbare-energien.de/EE/Navigation/DE/Gesetze/Das_EEG/das_eeg.html for an overview of the German Renewable Energy Act; legal texts; and a comparison of different amendments that were introduced over time. Most texts are available only in German. Accessed 15/09/16. 
- $T$ : Time in years for which the EEG guarantees payments.

- $1 \geq \delta>0$ : Discount factor.

- $q_{t}^{k}$ : Expected power production during year $t$ in $\mathrm{kWh}$ for a system of size $k^{5}$

- $m_{t}^{k}>0$ : EEG remuneration for a system of size $k$ in year $t$ per $\mathrm{kWh}$.

Aggregating these decisions on the municipality level, we can estimate a (reduced form) equation as a measure of how attractive it is to install PV systems in a municipality given municipality observables $x$. Clearly, bigger municipalities or those with higher solar radiation (large $q_{t}^{k}$ ) should have a higher probability of installations. As we argue in the next section, this reduced form equation generates the propensity score of a municipality, which is a measure of how comparable municipalities are in terms of their propensity to install PV systems. This measure allows us to compare pairs of municipalities $j$ and $l$ with the same predicted probability of installations $P\left(x_{j}\right)=P\left(x_{l}\right)$, where social effects are active in $j$ but inactive in $l$. Thus, if we match two comparable municipalities but observe systematic differences between them, then the difference must be due to social interaction (assuming the observables capture all relevant factors), because the fundamentals (propensity scores) are the same in the pairs by construction. The next section shows how this comparison is implemented using a matching approach.

\section{Method and data}

\subsection{Matching approach}

Denote the outcome of municipality $j$ at time $t$ absent treatment by $Y_{j t}^{0}$, the outcome of municipality $j$ with treatment by $Y_{j t}^{1}$, and the treatment status by $d_{j t} \in\{0,1\}$. Outcomes are the probability of at least one installation or the number of installations over one year starting at $t$. Treatment in our case means that municipality $j$ already has a PV system installed under the EEG legislation, hence others in the municipality may be influenced by it. The treatment effect therefore reflects all effects from having a PV system in the municipality on the PV installation decision.

Treatment status is time dependent in our setting. Municipality $j$ may be untreated at $t, d_{j t}=0$ (no system installed; no social effect due to existing systems), but it may be treated at some $t^{\prime}>t, d_{j t^{\prime}}=1$, because a system was installed. The econometric problem is identical in Sianesi (2004), where job seekers may be untreated at $t$ but treated at $t^{\prime}>0$.

\footnotetext{
${ }^{5}$ There exist various online tools for households to calculate the expected energy production (as well as costs) before installing a PV system. See, for instance, https://www.solarworld.de/service/ solarstromrechner/, http://www.renewable-energy-concepts.com/german/sonnenenergie/ basiswissen-solarenergie/pv-solar-rechner.html, accessed 2/4/2016. Moreover, the local company installing the systems will provide projections of yield in their offer.
} 
Consequently, as in Sianesi (2004), untreated units may be used at first as control and later as treatment observations.

We estimate the average treatment effect of the treated (ATT),

$$
\Delta_{\mathrm{ATT}}:=\mathbb{E}\left[Y_{j t}^{1}-Y_{j t}^{0} \mid d_{j t}=1\right] .
$$

As is well known, a direct estimate of the ATT is not possible, since the outcome for a municipality is not observed both when treated and untreated at the same time. If municipality $j$ is treated at $t$, then we observe $Y_{j t}^{1}$, but we do not observe what the outcome would have been if it had not been treated $\left(Y_{j t}^{0}\right)$. The matching approach relies on finding a comparable municipality $l$ that is untreated at $t$, so that its observed outcome $Y_{l t}^{0}$ equals the counterfactual $Y_{j t}^{0}$ on average.

For the identification of the ATT with the matching procedure, the standard conditional independence assumption (CIA) is sufficient. Formally, the CIA requires that, conditional on a vector of observable characteristics $x$, the potential outcome without treatment is independent from the treatment status,

$$
Y_{j t}^{0} \perp d_{j t} \mid x_{j t}
$$

Thus, the CIA requires that treated and untreated municipalities sharing the same characteristics $x_{j t}=x_{l t}$ draw $Y^{0}$ from the same distribution. This is fulfilled for the characteristics $x$ that determine whether a municipality installs PV systems without social effects, i.e., factors that form a kind of municipality 'PV system production function' absent treatment. Among those variables are the fundamentals that determine how attractive installing a PV system in municipality $j$ is (e.g., solar radiation), but also size variables and income that controls for the possibility of budget constraints in municipalities. A list of matching variables is discussed below.

Informally, our identification strategy exploits the fact that municipality outcomes $Y_{j t}^{0}$ given municipality characteristics $x_{j t}$ are not deterministic, so that differences in outcomes and hence treatment status are random given $x_{j t}$. That is, given the observables $x_{j t}$ and $x_{l t}$, municipalities $j$ and $l$ are comparable in that they predict a similar distribution of outcomes over the next year, but the actual (realized) outcomes may differ. By matching two with different treatment status realization, we observe both the outcome of the treated municipality and the outcome of the comparable untreated municipality.

As is standard in the literature, we solve the curse of dimensionality problem by matching on the propensity score. If the CIA holds based on $x_{j t}$, then it also holds with propensity score matching based on $x_{j t}$ (e.g., Rosenbaum and Rubin, 1983). Thus, we estimate the probability that at least one PV system is installed in municipality $j$ at $t$ over the next year given a vector of characteristics $x_{j t}$. We give a detailed description how we implemented the matching procedure in section 3.3. 
One critical point in the context of social interaction is the stable unit treatment value assumption, which requires that the treatment status of one municipality does not affect potential outcomes of other municipalities. Although we cannot rule out spillovers in single cases where a system is installed close to the border to another municipality, we expect that social effects are active only locally, i.e., affect others only in proximity (see, e.g., Graziano and Gillingham, 2015 or Rode and Weber, 2016 for prior evidence). Since the municipality level (our unit of observation) is larger/coarser than this, we expect social effects, if they exist, to affect others mostly in the same municipality. Note also that if control municipalities were somehow affected by PV systems in a neighboring municipality, then (given positive social effects) our treatment effect estimates would be conservative (i.e., biased downwards), since we would overestimate the counterfactual.

\subsection{Matching variables}

As the previous discussion shows, a valid matching procedure requires variables that explain the municipality production function of PV systems for a given year. In this section, we discuss the crucial variables that explain new PV installations on the municipality level.

Solar radiation. Holding capacity, angle towards the sun etc. of a PV system constant, power production and thus compensation under the EEG is increasing in solar radiation. Thus, it is more attractive to install a PV system in locations with higher solar radiation. We obtained spatial data of yearly solar radiation means over the years 1981-2010 for all $1 \mathrm{~km} \times 1 \mathrm{~km}$ cells in Germany from the German weather service, which are measured in $\mathrm{kWh} / \mathrm{m}^{2}{ }^{6}$ This data is displayed on a map in Figure 1. It is the best publicly available estimate of the PV potential in Germany. Many consumer guides or websites on PV systems provide similar solar radiation data to aid the decision whether to install a system, although these website data may be less precise (e.g., location determined via postal code is typically less accurate than our $1 \mathrm{~km} \times 1 \mathrm{~km}$ grid; see footnote 5 for two examples).

Inhabitants. All else equal, a larger municipality in terms of inhabitants should install more PV systems.

Number of (residential) buildings. Most of the PV systems in our data set are roof-mounted, and more buildings (i.e., roofs) may lead to more installations, all else equal. Controlling for both inhabitants and buildings allows us to distinguish municipalities with many inhabitants per building and those with few inhabitants per building.

Mean income. PV installations under the EEG are essentially a financial investment which additionally requires a roof (or ground structure) and whose return on investment depends on the location (see solar radiation above). Especially in the early years of the EEG, PV panel prices have been comparatively high, and the installation of a PV system

\footnotetext{
${ }^{6}$ These data also take into account local weather conditions, since a large number of cloudy days will reduce solar radiation, all else equal. $\mathrm{kWh}$ (kilowatt hour) is a unit of energy and $\mathrm{kWh} / \mathrm{m}^{2}$ is therefore the energy potential for a normalized area.
} 


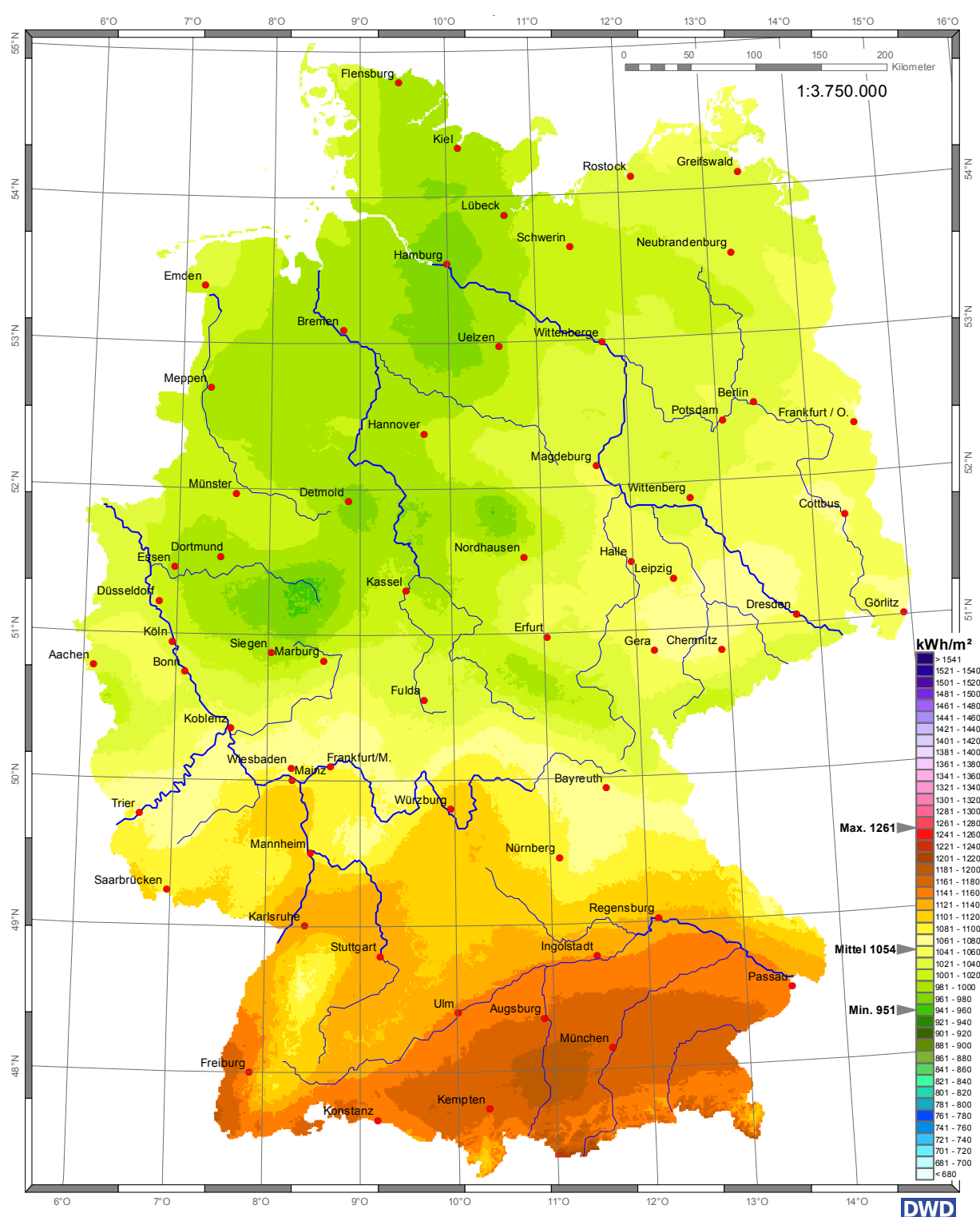

Figure 1: Map of solar radiation / solar energy potential in Germany; yearly means 1981-2010 in $\mathrm{kWh} / \mathrm{m}^{2}$; Source: German weather service (DWD)

required a large upfront payment. ${ }^{7}$ Consequently, all else equal, inhabitants of higher income municipalities are more likely to be able to afford the investment and to install more PV systems.

Political and ideological factors. We expect environmentally friendly citizens to be more likely to install PV systems in order to support the government efforts to expand the share of renewable energy in the energy production. On the municipality level, we have federal election results every four years, and we use the German green party ${ }^{8}$ vote share as

\footnotetext{
${ }^{7}$ Loans for the purpose of installing PV systems at favorable conditions are available from the government owned German Credit Bank (KfW) since 1999 (Schwarz, 2014, footnote 39). Still, the bank requires sufficiently good credit scores to approve the loan application, so it does not completely negate wealth constraints.

${ }^{8}$ Unlike in other countries, the German Green party has a strong presence in the political landscape, and has been part of governing coalitions on the federal level in two legislative periods (1998-2005) since
} 
our measure of environmental awareness among municipality inhabitants. All else equal, a higher green party vote share should lead to more PV installations. The vote shares of other parties (Conservative, Social-democrats, Left etc.) proxy for other ideological and political factors.

We further control for the area of the municipality as a measure of size, for population density as it might affect social interaction, for the unemployment rate as further control for the financial situation besides income, for the share of seniors as a measure of age composition, and for the federal election vote turnout. Moreover, we have various interactions between these variables. Overall, we use all available municipality level variables from the statistical state offices that could be expected to have an effect. And while an analysis on a finer geographical level might be desirable, most of the variables we use here would not be available.

We also include state fixed effects in the propensity score estimation to control for statewide factors. Moreover, since the time intervals for which we calculate the outcomes are the same for each matched control and treatment municipality, we effectively include time fixed effects as well. This is important since the EEG regulation was changed several times, and by comparing outcomes in the same time intervals we make sure that these changes impact treatment and control municipalities equally. Moreover, while installation costs do not differ much by region (since PV panels are bought from the international market and installation costs are a small part), they have decreased quite a lot over time. Our approach of exact matches by year accounts for this fact.

Table 1 shows summary statistics of the characteristics of all municipalities we have in our sample in year 2000 (the first year of our sample). The online appendix displays the propensity score estimations and lists all data sources with explanations.

\subsection{Implementation of the matching procedure}

In this section, we explain how we implemented the matching procedure; robustness checks and alternative specifications are discussed in section 5 .

In our main matching procedure, the propensity score is estimated separately each year based on a logit model. Hence, we estimate the probability of at least one PV installation within year $t$ in municipality $j$ given observables $x_{j t}$ with observations from the pool of all untreated municipalities at the beginning of years $t=2000,2001, \ldots, 2010$. The advantage of estimating the propensity score by year rather than over all years is that we not only allow for the constant in the probability of treatment to vary by year (like a year fixed effect), but we also allow all slope parameters of the covariates to vary by year, thus greatly improving the flexibility of our specification.

its foundation in 1980. Moreover, the EEG system was enacted with the Greens as part of the governing coalition and driving force. 
Table 1: Municipality Level Summary Statistics

\begin{tabular}{lcccc}
\hline & Mean & SD & Min & Max \\
\hline Total area (in ha) & $2,703.61$ & $3,127.61$ & 42.00 & $40,515.00$ \\
Residential buildings & $1,398.33$ & $3,963.34$ & 8.00 & $126,349.00$ \\
Inhabitants & $6,453.20$ & $27,174.61$ & 19.00 & $1,234,692.00$ \\
Mean income (in 1000 €) & 30.31 & 7.56 & 8.00 & 272.57 \\
Unemployment rate & 0.04 & 0.03 & 0.00 & 0.28 \\
Global radiation (in kWh $\left./ \mathrm{m}^{2}\right)$ & $1,059.39$ & 54.81 & 958.00 & $1,192.00$ \\
Population density $(\mathrm{number} / \mathrm{ha})$ & 1.88 & 2.67 & 0.03 & 39.77 \\
Share seniors & 0.17 & 0.04 & 0.00 & 0.41 \\
Votes Green & 0.06 & 0.03 & 0.00 & 0.38 \\
Votes Conservative & 0.44 & 0.14 & 0.08 & 0.96 \\
Votes Soc-Dem & 0.36 & 0.11 & 0.02 & 0.73 \\
Votes Liberals & 0.07 & 0.03 & 0.00 & 0.52 \\
Votes Left & 0.04 & 0.06 & 0.00 & 0.37 \\
Votes others & 0.03 & 0.02 & 0.00 & 0.17 \\
Voter turnout & 0.75 & 0.08 & 0.37 & 0.98 \\
\hline Observations & 10905 & & & \\
\hline
\end{tabular}

Note: Summary statistic refers to the universum of municipalities in 2000.

In the propensity score logit specification for each year, we use all variables discussed above as second degree polynomials, and add interactions of the number of inhabitants with mean income, the population density, the voter turnout, and the share of seniors. Different specifications using the same set of variables yield the same conclusions. In addition to these variables and interactions, we use state fixed effects to capture possible state-wide factors that might influence aggregate PV installations.

We use a nearest neighbor matching procedure with replacement on the estimated propensity scores, with one control municipality matched to each treatment municipality, and each control municipality is allowed to be matched to several different treatment municipalities. Given our large sample size and given that we match with replacement, we use an ambitious caliper of 0.01 , i.e., if there is no control municipality with a propensity score difference of one percentage point or less, then we drop the treatment observation. This ensures almost exact matches in terms of the propensity score. Moreover, we enforce a common support among treatment and control municipalities. The common support ensures that the pools of treatment and control municipalities are similar. The combination of the 1-nearest-neighbor match, replacement, the ambitious caliper, and the common support are all aimed at minimizing bias rather than variance since we have a large number of observations. Given the propensity scores, the matching procedure can be represented by the following algorithm.

For each municipality $i$ which had at least one installation during the sample period: 
1. Find date $t_{i}$ of the first EEG PV installation in municipality $i$ (time of treatment)

2. Find municipality $j \neq i$ in the common support without installations at time $t_{i}$ which is closest in propensity score $p\left(x_{j t_{i}}\right)$ to $p\left(x_{i t_{i}}\right)$ ( $j$ is control municipality for $i$ )

3. If $\left|p\left(x_{j t_{i}}\right)-p\left(x_{i t_{i}}\right)\right|>0.01$, then discard municipality $i$ (caliper matching: match not good enough); otherwise proceed to 4 .

4. Take the difference in outcomes over the following year, i.e., from time $t_{i}$ to $t_{i}+1$ between $i$ and $j$

Finally, we average these differences over all matched pairs $i$ and $j$ to obtain the average treatment effect on the treated.

\subsection{Matching quality}

The online appendix assesses the quality of the match produced by the main model in detail. In short, while the set of treatment and the set of control municipalities differs considerably prior to matching, there are no significant differences left in terms of the propensity score distribution or the distribution of single covariates after matching. Figure 2 displays the distribution of the covariates for both treatment and control municipalities after matching. The two graphs are very similar for all variables. Tests for differences in means yield no significiant differences (see online appendix). Thus, the quality of the matches is very good, as we would expect given the ambitious caliper with replacement. Based on observable characteristics, our matching procedure was able to produce a balanced sample. The online appendix shows and discusses the propensity score estimations.

\section{Results}

\subsection{The effect of social interaction on PV installations}

Before analyzing the impact of social interactions on the allocative efficiency of the policy, we ask: What role did social interactions play in the EEG-subsidized expansion of solar energy in Germany? We compute the ATT for three outcome variables: the probability of installing at least one PV system in the municipality, the number of PV systems installed, and the number of systems per 1000 inhabitants within one year. ${ }^{9}$ Recall that we compare the probability/number of further installations in the treatment group (since treatment implies that one system was installed) within a year with the probability/number of PV

\footnotetext{
${ }^{9}$ Note that the number of PV installations as measure underestimates the effect if social effects are positive, since the control municipality is untreated only until the first system is installed, and afterwards social interaction may take effect. The probability outcome measure, on the other hand, does not underestimate the effect, since the indicator does not distinguish between one or more installations.
} 

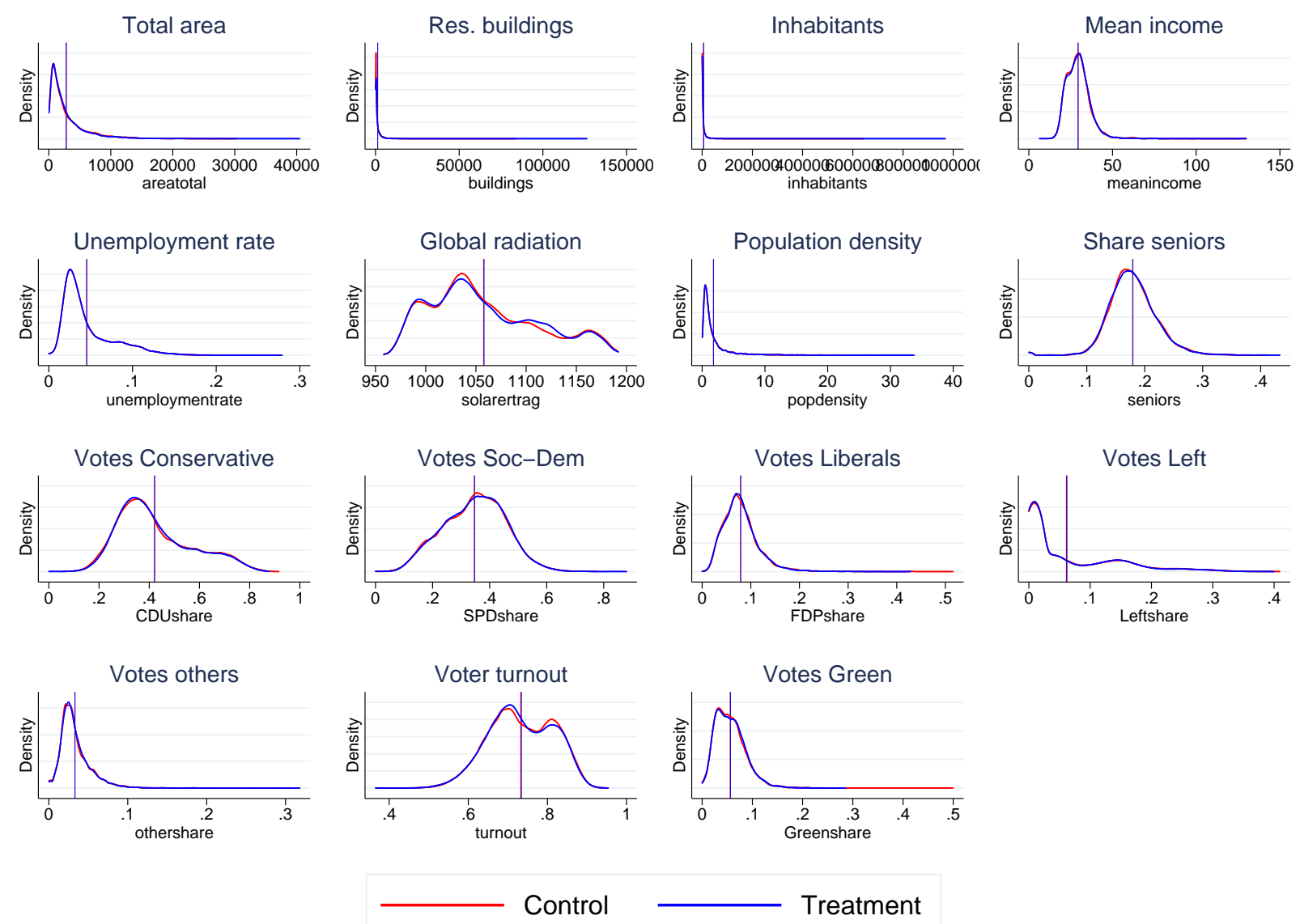

Figure 2: Distribution of covariates after matching for treatment and control group (with group means as vertical lines)

installations in the matched control group in the same time interval. The average treatment effects on the treated are displayed in Table 2. On all outcome variables, the estimated treatment effect (effect of social interaction) is positive and statistically significant. ${ }^{10}$ This finding is consistent with the previous literature.

The probability of at least one PV installation approximately increases by about a quarter due to social interaction, from about $49 \%$ in the matched control group to about $60 \%$ in the treatment group. The number of installations increases by about a half, increasing the number from about 1.6 to about 2.4 PV installations within a year on average. Finally, the number of installations per 1000 inhabitants increases by more than half from 0.85 to about 1.44 within a year.

Result 1. Social effects increase the number and probability of further PV installations.

\footnotetext{
${ }^{10}$ Since our matching procedure allows municipalities to be matched at different times (and therefore with potentially different outcomes), we cluster standard errors to account for this dependence in the observations. In recent work, Abadie and Spiess (2016) recommend clustering standard errors for postmatching regressions - as we conduct in this section - albeit with nearest neighbor matching (we are not aware of similar work for propensity score matching). The matching standard errors of Abadie and Imbens (2016) are not valid for our main matching procedure; we still compute them for a robustness check in section 5 and these do not change our conclusions.
} 
Table 2: Average treatment effects on the treated over one year

\begin{tabular}{lccc}
\hline & $(1)$ OLS & $(2)$ OLS & $(3)$ OLS \\
Dependent variable & ProbInstall & NumInstall & NumInstall per 1000 \\
\hline Treatment & $\begin{array}{c}0.118^{* * *} \\
(0.007)\end{array}$ & $\begin{array}{c}0.800^{* * *} \\
(0.065)\end{array}$ & $\begin{array}{c}0.587^{* * *} \\
(0.040)\end{array}$ \\
Constant & $0.487^{* * *}$ & $1.575^{* * *}$ & $0.845^{* * *}$ \\
& $(0.006)$ & $(0.059)$ & $(0.034)$ \\
\hline $\mathrm{R}^{2}$ & 0.01 & 0.01 & 0.01 \\
Observations & 22284 & 22284 & 22284 \\
Clusters & 10712 & 10712 & 10712 \\
\hline
\end{tabular}

Note: ProbInstall is the probability of at least one new panel within a year, NumInstall is the number of new panels within a year, and NumInstall per 1000 is the number of new panels within a year per 1000 inhabitants. Standard errors are clustered at the municipality level. ***Significant at the $1 \%$ level; ** significant at the $5 \%$ level; *significant at the $10 \%$ level.

To foreshadow the results of the robustness section, we did not find a single specification without positive and significant treatment effects. Thus, social interaction had an economically large and statistically significant impact on the investment decision and thereby on the expansion of renewable energy. It therefore appears not to be the case that individuals make their investment decisions in isolation, but are affected by neighbors or spatially close households. In particular, social interaction can explain a large part of the high participation rate in the EEG-program.

\subsection{Heterogeneous treatment effects}

Are social effects stronger in municipalities with particular characteristics? For example, are social effects stronger in small close-knit municipalities? Or are they stronger in southern areas with more solar radiation, where it is more attractive to install PV systems? We investigate these questions by comparing how the outcomes change by characteristic in both treatment and control group. The regression results for all outcome variables are given in Table 3. The interactions of the treatment dummy with the municipality characteristics are the average changes of the treatment effect in the characteristic (holding other characteristics constant).

We will discuss only the most important results. First, more solar radiation increases the treatment effect on the number of installations, but not for the other outcome variables. This result suggests that solar radiation works on the intensive margin, but not on the extensive margin of the social effects. Second, the treatment effect decreases in the vote share for the green party. This is surprising, since the probability and number of PV installations increases significantly in the vote share for the green party absent treatment. The result might suggest that municipalities with more inhabitants motivated by environmental con- 
Table 3: Average treatment effects on the treated over one year by municipality characteristics

\begin{tabular}{|c|c|c|c|}
\hline & (1) OLS & (2) OLS & (3) OLS \\
\hline Dependent variable & ProbInstall & NumInstall & NumInstall per 1000 \\
\hline Treatment & $\begin{array}{c}0.568^{* * *} \\
(0.148)\end{array}$ & $\begin{array}{c}-4.245^{* * *} \\
(1.382)\end{array}$ & $\begin{array}{c}3.143^{* * *} \\
(1.140)\end{array}$ \\
\hline Treatment $\times$ Solar radiation & $\begin{array}{l}-0.000 \\
(0.000)\end{array}$ & $\begin{array}{c}0.006^{* * *} \\
(0.001)\end{array}$ & $\begin{array}{l}-0.001 \\
(0.001)\end{array}$ \\
\hline Treatment $\times$ Voteshare green & $\begin{array}{c}-0.689^{* * *} \\
(0.266)\end{array}$ & $\begin{array}{l}-3.918^{*} \\
(2.219)\end{array}$ & $\begin{array}{c}-14.914^{* * *} \\
(4.978)\end{array}$ \\
\hline Treatment $\times$ Total area & $\begin{array}{l}-0.000 \\
(0.000)\end{array}$ & $\begin{array}{l}0.000^{*} \\
(0.000)\end{array}$ & $\begin{array}{c}-0.000^{* * *} \\
(0.000)\end{array}$ \\
\hline Treatment $\times$ Inhabitants & $\begin{array}{l}0.000^{*} \\
(0.000)\end{array}$ & $\begin{array}{c}0.000 \\
(0.000)\end{array}$ & $\begin{array}{c}0.000^{* *} \\
(0.000)\end{array}$ \\
\hline Treatment $\times$ Buildings & $\begin{array}{c}-0.000^{*} \\
(0.000)\end{array}$ & $\begin{array}{l}-0.000 \\
(0.000)\end{array}$ & $\begin{array}{c}-0.000^{* *} \\
(0.000)\end{array}$ \\
\hline Treatment $\times$ Population density & $\begin{array}{c}0.000 \\
(0.004)\end{array}$ & $\begin{array}{l}-0.105 \\
(0.105)\end{array}$ & $\begin{array}{c}-0.051^{* *} \\
(0.024)\end{array}$ \\
\hline Treatment $\times$ Unemployment & $\begin{array}{c}-1.142^{* * *} \\
(0.249)\end{array}$ & $\begin{array}{c}-14.554^{* * *} \\
(1.725)\end{array}$ & $\begin{array}{c}-16.976^{* * *} \\
(2.506)\end{array}$ \\
\hline Treatment $\times$ Mean income & $\begin{array}{c}-0.007^{* * *} \\
(0.001)\end{array}$ & $\begin{array}{c}-0.014 \\
(0.011)\end{array}$ & $\begin{array}{l}-0.008 \\
(0.023)\end{array}$ \\
\hline Treatment $\times$ Share seniors & $\begin{array}{l}-0.149 \\
(0.172)\end{array}$ & $\begin{array}{l}-1.230 \\
(0.802)\end{array}$ & $\begin{array}{c}3.599 \\
(2.491)\end{array}$ \\
\hline Solar radiation & $\begin{array}{c}0.002^{* * * *} \\
(0.000)\end{array}$ & $\begin{array}{c}0.016^{* * *} \\
(0.001)\end{array}$ & $\begin{array}{c}0.001 \\
(0.001)\end{array}$ \\
\hline Voteshare green & $\begin{array}{l}0.322^{*} \\
(0.183)\end{array}$ & $\begin{array}{c}4.632^{* * *} \\
(1.749)\end{array}$ & $\begin{array}{l}7.934^{*} \\
(4.298)\end{array}$ \\
\hline Total area & $\begin{array}{c}0.000^{* * *} \\
(0.000)\end{array}$ & $\begin{array}{c}0.000 * * * \\
(0.000)\end{array}$ & $\begin{array}{c}-0.000^{* * *} \\
(0.000)\end{array}$ \\
\hline Inhabitants & $\begin{array}{c}-0.000^{* * *} \\
(0.000)\end{array}$ & $\begin{array}{c}0.000 \\
(0.000)\end{array}$ & $\begin{array}{c}0.000^{* * *} \\
(0.000)\end{array}$ \\
\hline Buildings & $\begin{array}{c}0.000^{* * *} \\
(0.000)\end{array}$ & $\begin{array}{l}0.000^{* *} \\
(0.000)\end{array}$ & $\begin{array}{l}-0.000 \\
(0.000)\end{array}$ \\
\hline Population density & $\begin{array}{c}0.017^{* * *} \\
(0.003)\end{array}$ & $\begin{array}{c}0.038 \\
(0.068)\end{array}$ & $\begin{array}{c}-0.184^{* * *} \\
(0.017)\end{array}$ \\
\hline Unemployment & $\begin{array}{c}-1.437^{* * *} \\
(0.156)\end{array}$ & $\begin{array}{l}-1.592^{*} \\
(0.889)\end{array}$ & $\begin{array}{c}-5.456^{* * *} \\
(1.257)\end{array}$ \\
\hline Mean income & $\begin{array}{c}0.006^{* * *} \\
(0.001)\end{array}$ & $\begin{array}{c}0.003 \\
(0.009)\end{array}$ & $\begin{array}{l}-0.012 \\
(0.010)\end{array}$ \\
\hline Share seniors & $\begin{array}{c}0.372^{* * *} \\
(0.126)\end{array}$ & $\begin{array}{c}0.074 \\
(0.760)\end{array}$ & $\begin{array}{l}3.548 * * \\
(1.466)\end{array}$ \\
\hline Constant & $\begin{array}{c}-1.782^{* * *} \\
(0.112)\end{array}$ & $\begin{array}{c}-16.341^{* * *} \\
(1.451)\end{array}$ & $\begin{array}{c}0.016 \\
(0.740)\end{array}$ \\
\hline $\mathrm{R}^{2}$ & 0.17 & 0.29 & 0.05 \\
\hline Observations & 22284 & 22284 & 22284 \\
\hline Clusters & 10712 & 10712 & 10712 \\
\hline
\end{tabular}

Note: ProbInstall is the probability of at least one new panel within a year. NumInstall is the number of installations within a year, and NumInstall per 1000 is the number of installation per 1000 inhabitants within a year. Standard errors are clustered at the municipality level. ***Significant at the $1 \%$ level; ** significant at the $5 \%$ level; *significant at the $10 \%$ level. 
cerns (rather than financial reasons) are not influenced as much by others. Third, the effect of social interaction decreases in the unemployment rate for all outcome variables. Since solar panels are comparatively expensive investments, it is not surprising that households in municipalities with high unemployment are not as much influenced by others, as they may not be able to afford the investment. Size variables such as area, inhabitants and number of residential buildings do not unambiguously change the magnitude of the social effects.

The number of installations increasing with solar radiation and decreasing with unemployment might suggest that social effects are stronger where it is more attractive to install them (more solar radiation, more likely to be able to afford the PV panels).

Result 2. The social effect is stronger in municipalities with lower unemployment and a lower vote share for the green party. More solar radiation increases the social effect on the number of installations.

\subsection{Main result: Effects by solar radiation and efficiency}

From a policy perspective, it is important to ask whether social interaction accounts for installations even in areas with minimal solar radiation, where it might be inefficient to install them. These same PV systems in low radiation areas could be installed at about the same cost in municipalities with more solar radiation, and, all else equal, the power output of a system increases linearly in solar radiation. Thus, if the policy aims at maximizing renewable energy production for a given budget, then systems in low radiation areas are evidence of inefficiency.

An advantage of the matching approach is that it allows computation of local treatment effects rather than one average effect. Thus, we can compute the treatment effect for each treated municipality by taking the outcome difference of the treatment municipality and the matched control municipality. We can then locally average the results with nonparametric methods. Figures 3a and 3b display the local average treatment effects by solar radiation of the treatment municipality with polynomial smoothing. First, for the probability of installations, Figure 3a shows that the treatment effect is significantly positive for the entire range of solar radiation levels in the sample. Second, for the number of installations, Figure $3 \mathrm{~b}$ shows that the social effects are never significantly negative, and significantly positive for most of the solar radiation range (except close to the minimum and maximum sample values). Third, the effect of others on installations appears to be strongest in the upper range of solar radiation levels between 1100 and $1150 \mathrm{kWh} / \mathrm{m}^{2}$ for both outcome variables. Fourth, in the interquartile range (inner 50\% of municipalities) between 1017 and 1097 $\mathrm{kWh} / \mathrm{m}^{2}$, the social effect varies only slightly by solar radiation, whereas the outer quartiles show more variation.

Thus, social effects appear to cause installations in areas with low solar radiation, which could produce considerably more energy further south, which is inefficient. Consequently, 


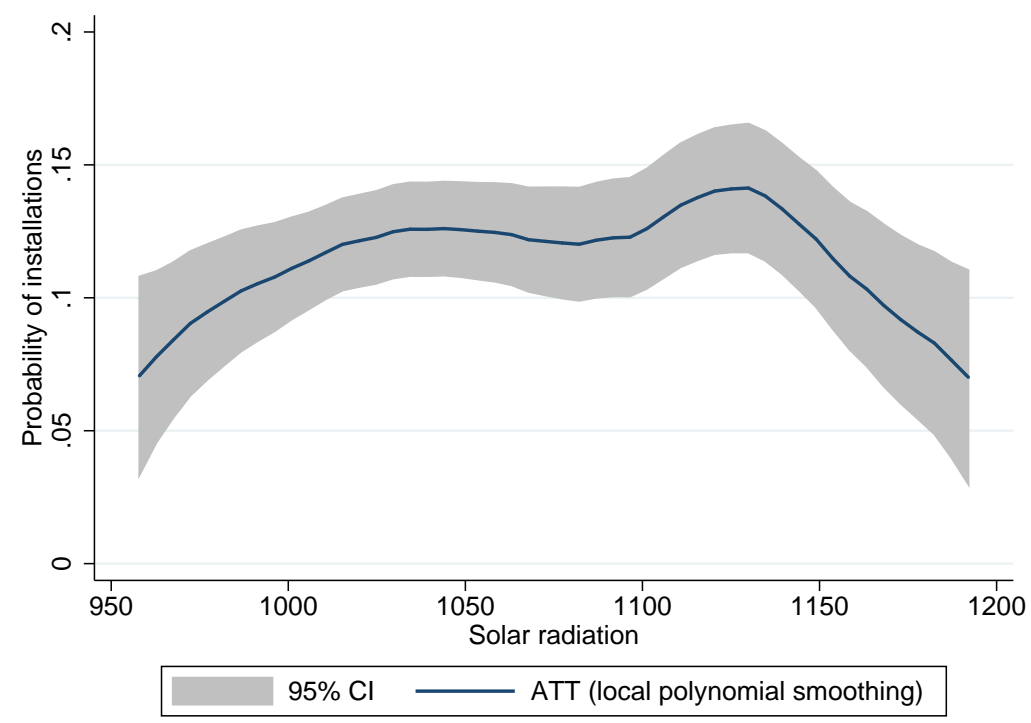

(a) Probability to install at least one PV system

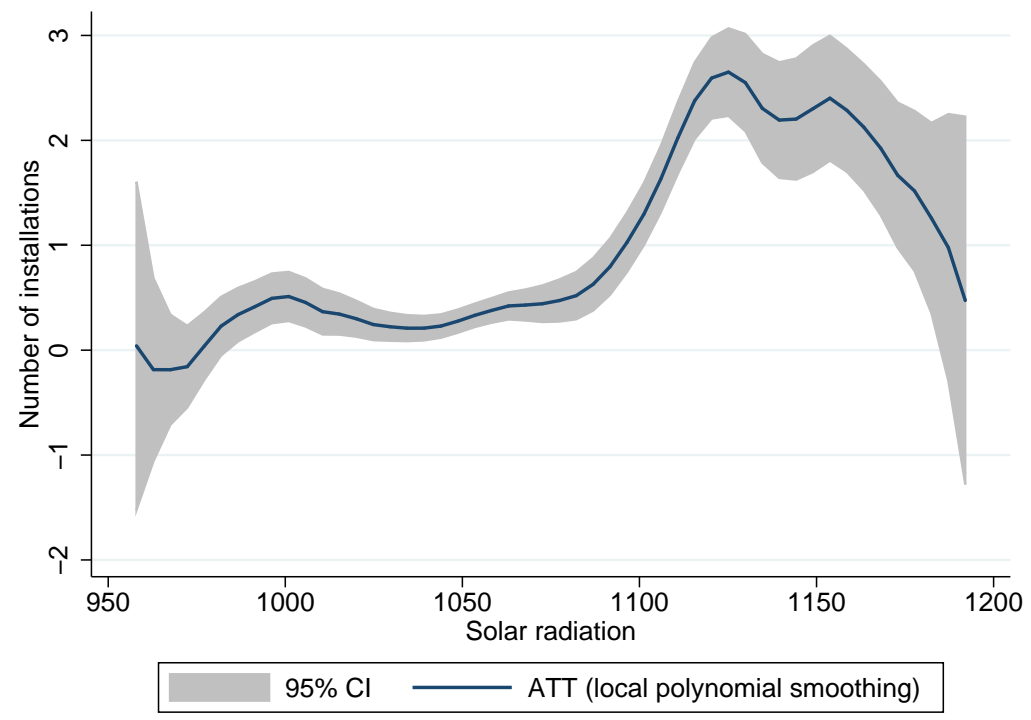

(b) Number of PV systems

Figure 3: The ATT by solar radiation (in $\mathrm{kWh} / \mathrm{m}^{2}$ )

the presence of social effects may make an inefficient minimum price policy even worse. We elaborate on this possible interaction of social effects with the non-competitive policy design in the policy implications below.

Result 3. The social effect on the probability of installations is positive at all sample values of solar radiation, and positive on the number of installations in the interior range of solar radiation levels. 


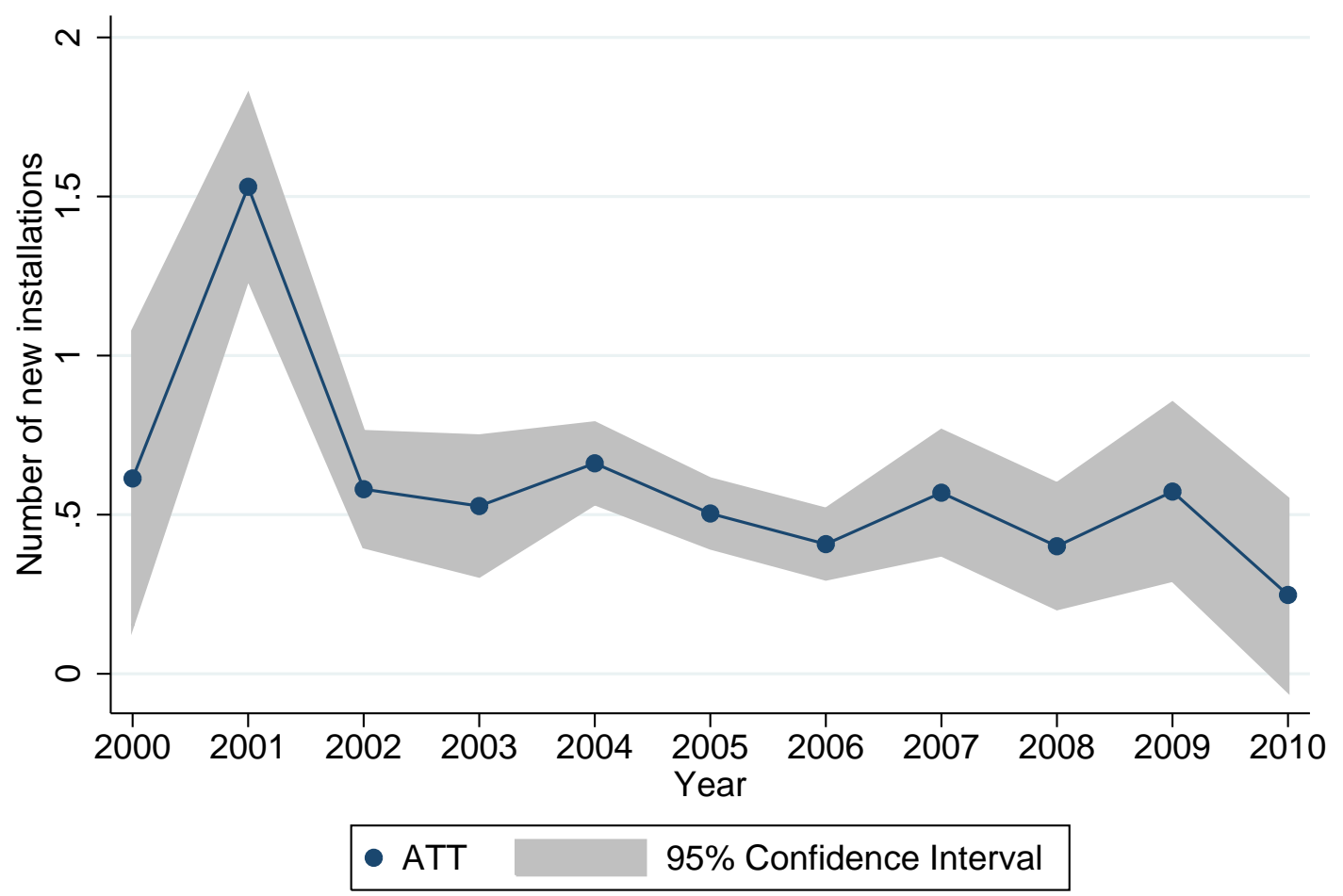

Note: clustered standard errors on municipality level

Figure 4: The ATT on the number of new installations by year

\subsection{Treatment effects by year}

Are social effects stronger in the early years of the regulation, or do they pick up only after a while? To address this question, we calculate the ATT separately for each year using all municipalities that were treated (i.e., installed their PV system) in this year. Consequently, the ATT for year 2000 is the ATT of all municipalities who had their first installation in year 2000. Figure 4 displays the ATT on the number of installations within one year, since this measure directly captures the expansion of PV systems. The ATT is strongest in the year following the introduction of the EEG. In the years thereafter, the effect appears to be very slightly decreasing. A potential explanation for this finding is that households expect a decreasing feed-in tariff over time, but this seems rather unlikely, since such an expectation should affect both control and treatment municipalities. Instead, the strong year 2001 might suggest that social interaction helped spread the word about the profitable PV subsidy when it was not yet well known. Or it might be strongest in this early year simply because sunnier municipalities are overrepresented - since they have a larger propensity score - and the effects are stronger in these municipalities (see previous paragraphs on heterogeneous treatment effects).

To check this alternative possibility, we control for the propensity score of the munici- 


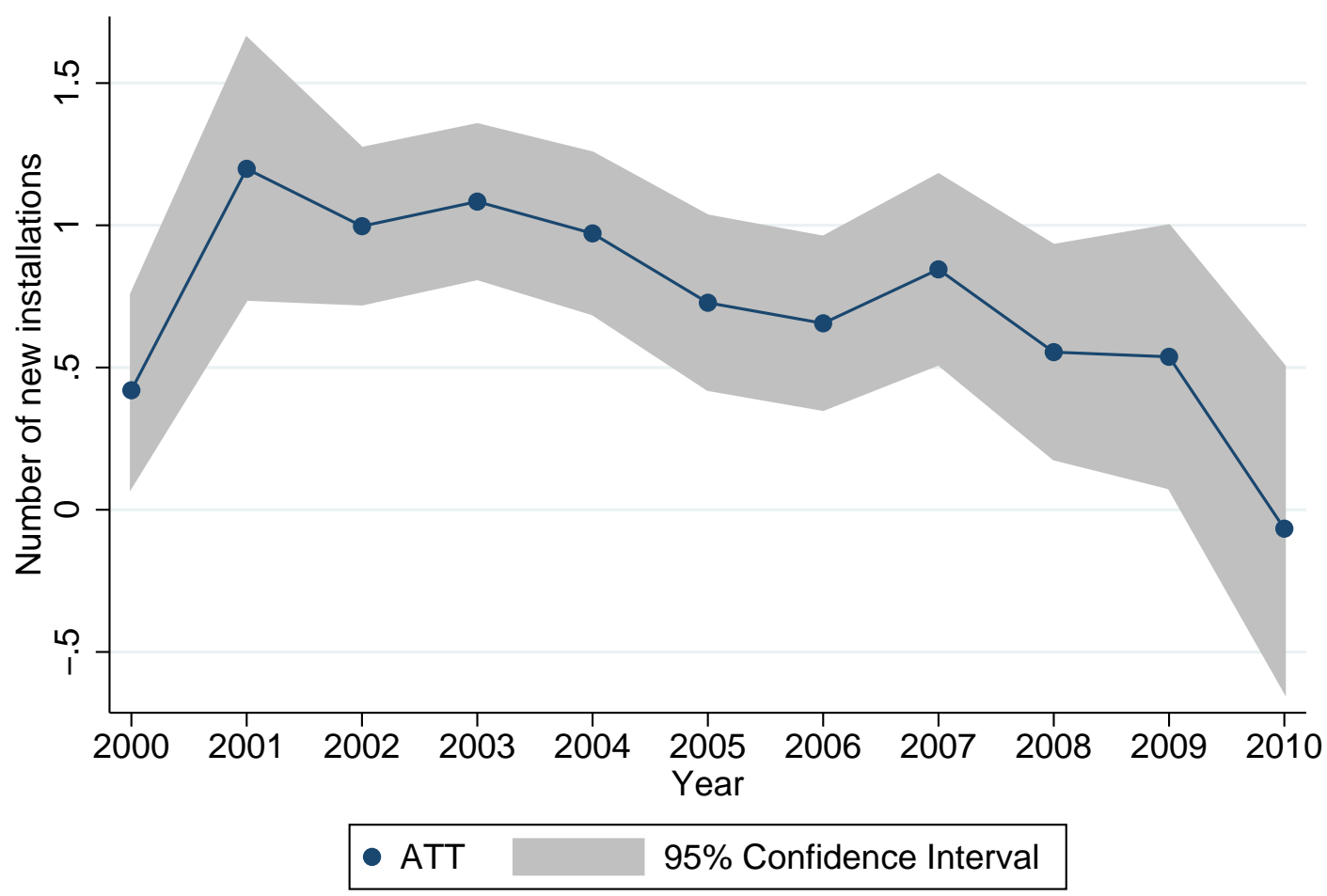

Note: clustered standard errors on municipality level

Figure 5: The ATT on the number of new installations by year, controlled for the propensity score of the municipality, evaluated at the mean propensity score 0.45 (see (2) for the estimated equation)

palities when calculating the ATT by year, which accounts for the probability of treatment:

$$
y_{i t}=\alpha^{\prime} \text { Treatment }_{i t} \times \text { Year }_{i t}+\beta \text { Treatment }_{i t} \times \text { PScore }_{i t}+\gamma^{\prime} \text { Year }_{i t}+\delta \text { PScore }_{i t}+\varepsilon_{i t},
$$

where Year $_{i t}$ is a column vector of dummies for years 2000, 2001, ., 2010 (which absorbs the constant), and PScore $i t$ is the propensity score of municipality $i$ in year $t$. Thus, in this specification, the treatment effect may vary by year and by propensity score, which allows us to determine how the treatment effect varies by year $(\alpha)$ after controlling for propensity scores.

The resulting ATT estimates are displayed in Figure 5. The graph shows that the spike in 2001 is considerably smaller once we control for the propensity to install new PV systems. There appears to be a slightly decreasing time trend after controlling for the propensity score. However, a formal test for a linear time trend gives a significant negative trend only at the $10 \%$ significance level. Our conclusion is that social effects appear to be stronger in the early years, but a lot of this annual difference is due to "better" municipalities with larger propensity score - where social effects are stronger-being treated in the early years.

Result 4. The social effect was strongest in 2001 shortly after the introduction of the policy, but this difference can be explained by sunnier and bigger municipalities getting treated 
earlier.

\subsection{Treatment intensity}

So far we assumed that 'treatment' is the installation of one PV system in a municipality, hence the treatment effect reflected the effect of one system in the municipality versus no system in the municipality (control group). We now ask how the effects change if treatment intensity varies, i.e., if there are two, three, four or five instead of one system in the municipality (compared to zero in the control municipality). Thus, we run our matching routine with the same specification as before, except we define treatment as starting once the second, third, etc. system was installed.

Figures $6 \mathrm{a}$ and $6 \mathrm{~b}$ display the average treatment effect on the treated by treatment intensity. As expected, the treatment effects increase in treatment intensity both for the probability of further installations within a year as well as for the number of further installations. For the probability of further installations, the treatment effect appears to be concave in treatment intensity. By modeling the treatment effect as second degree polynomial, we can carry out a simple formal test for this observation when pooling the matching data sets for all intensities:

$$
\begin{array}{r}
y_{i t}=\alpha \text { Treatment }_{i t}+\beta \text { Treatment }_{i t} \times \text { Intensity }_{i t}+\gamma \text { Treatment }_{i t} \times \text { Intensity }_{i t}^{2} \\
+\delta^{\prime} \text { Intensity }_{i t}+\varepsilon_{i t},
\end{array}
$$

where Intensity ${ }_{i t}$ is a dummy indicating treatment intensity of the matched pair (which absorbs the constant), and Intensity ${ }_{i t}$ is the scalar value of the intensity. The test for concavity is $\gamma<0$. We estimate $\gamma=-.0148(t=-6.62)$, so the treatment effect on the probability of further installations is concave in treatment intensity in this second order polynomial approximation.

For the number of further PV installations in Figure 6b, the treatment effect appears to be slightly convex in treatment intensity. The test for convexity is $\gamma>0$, however, we obtain $\gamma=0.028(t=1.64)$, so we cannot reject linearity of the treatment effect in intensity on the number of further installations at the $5 \%$ significance level.

Interestingly, for the number of installations, the 'marginal' increase is the largest for the first system. This has important implications for policy makers that wish to boost installations in certain areas. The first system may be considered a "seed" system, and these results may give a justification to introduce encouragement policies that are targeted at areas with no or only a few installations (for a similar argument, see Rode and Weber, 2016).

Result 5. The social effect is stronger with more existing systems in the municipality. While the social effect increases approximately linearly for the number of installations in intensity, it is concave in intensity for the probability of further installations. 


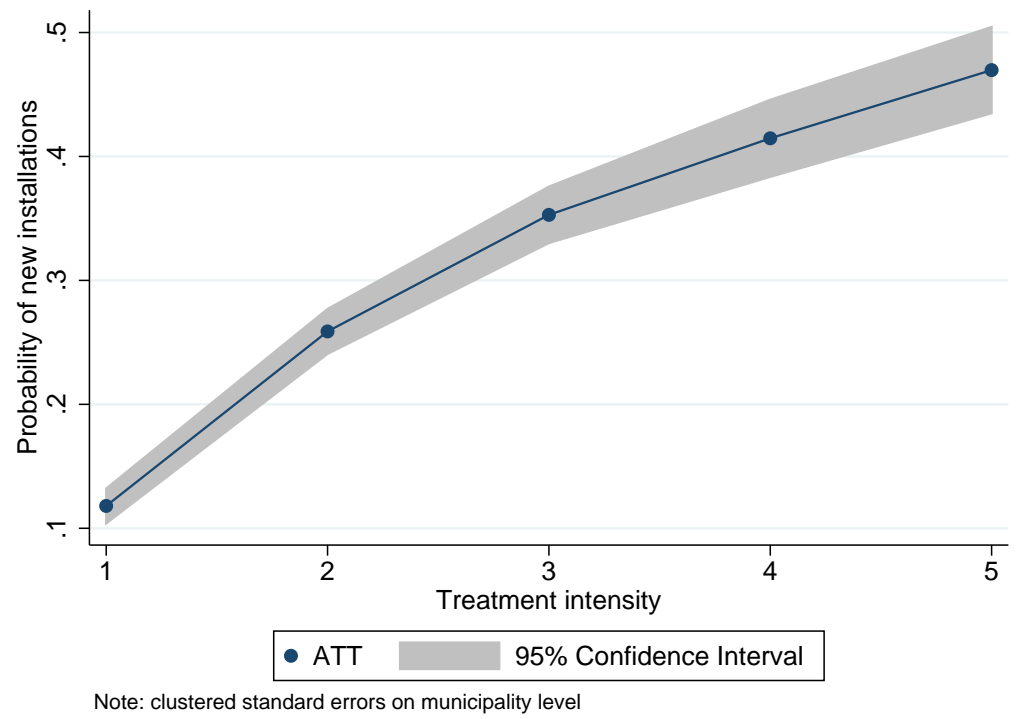

(a) Probability to install at least one PV system

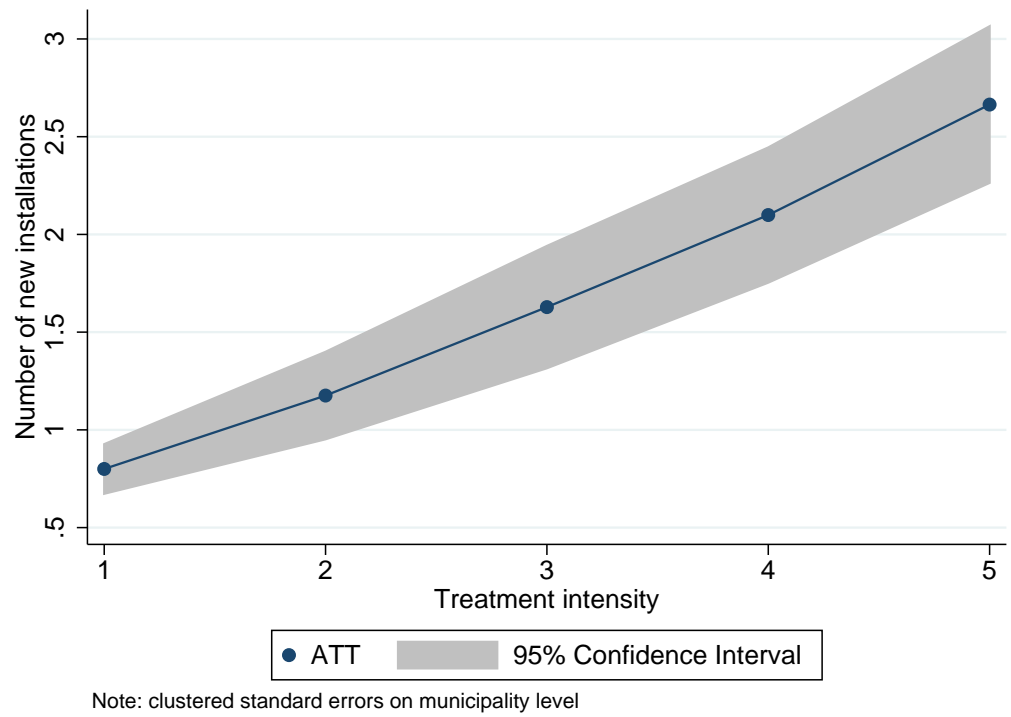

(b) Number of PV systems

Figure 6: The ATT by treatment intensity (number of existing systems in the municipality)

Accounting for history. If treatment starts not at the first installed system in the municipality, but with installation of the Kth system $(K>1)$, then the history of PV system installations can differ between treatment municipalities. For example, if treatment starts with the installation of the second system, then the installation of the first system may have occurred immediately before the second, or years before. The estimates in Figures 6a and $6 \mathrm{~b}$ give the average effect over all histories in our sample. Now we want to investigate if the social effect is stronger if several systems have been recently installed, i.e., how the social effect changes by installation history.

The history variables of interest are the time intervals between the installations and the treatment start. For the treatment start at installation of $K$ systems, the history is 
Table 4: Average treatment effects on the treated by panel installation history

\begin{tabular}{lcccccc}
\hline & $(1)$ OLS & $(2)$ OLS & $(3)$ OLS & $(4)$ OLS & (5) OLS & $(6)$ OLS \\
& $K=2$ & $K=2$ & $K=3$ & $K=3$ & $K=4$ & $K=4$ \\
Dependent variable & ProbInstall & NumInstall & ProbInstall & NumInstall & ProbInstall & NumInstall \\
\hline Treatment $\times d_{1}$ & $-0.090^{* * *}$ & $-1.259^{* * *}$ & $-0.056^{* * *}$ & $-1.214^{* * *}$ & $-0.032^{* * *}$ & $-1.205^{* * *}$ \\
& $(0.008)$ & $(0.094)$ & $(0.008)$ & $(0.107)$ & $(0.009)$ & $(0.108)$ \\
Treatment $\times d_{2}$ & & & $-0.034^{* *}$ & $-0.769^{* * *}$ & -0.021 & $-0.517^{* * *}$ \\
& & & $(0.015)$ & $(0.193)$ & $(0.016)$ & $(0.194)$ \\
Treatment $\times d_{3}$ & & & & -0.033 & $-0.766^{* * *}$ \\
& & & & $(0.022)$ & $(0.265)$ \\
\hline FE PS group & & & & yes & yes \\
R & & & & & 0.00 & 0.03 \\
Observations & 0.01 & 0.01 & 0.01 & 0.02 & 17832 & 17832 \\
\hline
\end{tabular}

Note: ProbInstall is the probability of at least one new panel within a year and NumInstall is the number of new panels within a year. $d_{k}$ is the time since installation of the kth panel at treatment start in 1000 days. Standard errors are clustered at the propensity score group level; group $g=1, \ldots, 100$ has a propensity score in $(g-1, g] .{ }^{* * *}$ Significant at the $1 \%$ level; ${ }^{* *}$ significant at the $5 \%$ level; ${ }^{*}$ significant at the $10 \%$ level.

$\left\{d_{k}\right\}_{k=1, \ldots, K}$, where $d_{k}$ is the time (distance) between installation of the $\mathrm{k} t h$ system and time of treatment. Because treatment starts at installation of the Kth system, we have $d_{K}=0$, and the relevant history that may differ between municipalities is $\left\{d_{1}, \ldots, d_{K-1}\right\}$. To account for the history, we could use interactions with the treatment dummy in an OLS regression on the matched sample:

$$
y_{i t}=\alpha \text { Treatment }_{i t}+\beta^{\prime} \text { Treatment }_{i t} \times \mathbf{d}_{i t}+\gamma+\varepsilon_{i t},
$$

where $\mathbf{d}_{i t}=\left(d_{1}, \ldots, d_{K-1}\right)^{\prime}$ is the vector of the times between installation of the $K-1$ old systems and treatment start. The effect of the history $\beta$ would be estimated solely from variation between treatment municipalities, since control municipalities all have the same history (no installations). However, treatment municipalities may not necessarily be comparable, since our matching approach aimed at making treatment and control municipalities comparable. Thus, large sunny treatment municipalities likely have more concentrated installations (small values of $d_{k}$ ) and also likely have more installations in the future, compared to smaller treatment municipalities with less sun, which might give a negative effect of history $(\beta<0)$ due to the between-treatment-municipality comparison even if the true effect is zero.

To make treatment municipalities comparable, we use the propensity scores we already estimated for matching with control municipalities. In principle, we want to run regression (3) only for treatment municipalities in a narrow propensity score interval, say for municipalities with propensity score in $[0.9,0.91]$, which ensures that the effect of history is estimated from variation within comparable treatment municipalities. Since it is impractical to run 
many different regressions on different subintervals, we use the within estimator, i.e., a single fixed effects regression with a fixed effect for each propensity score interval. This allows us to estimate the effect of history within propensity score groups, rather than between groups as in (3).

Table 4 reports the results of the within estimator for treatment intensity $K=\{2,3,4\}$. We use 100 propensity score groups with a 1 percentage point interval for the treatment municipalities and 100 groups for the control municipalities. Thus, the treatment dummy is constant within each group, and we only estimate the coefficients for the history variables that vary within groups.

If treatment starts at two systems in the municipality $(K=2)$, the only relevant history is how long ago the first system was installed when treatment started $\left(d_{1}\right)$. Table 4 shows that the effect of distance is significantly negative for all outcome variables. On average, if the first system was installed 1000 days prior to the second system $\left(d_{1}=1\right)$, then the social effect on the probability of further installations after the second system is 9 percentage points lower compared to the case of $d_{1}=0$. Moreover, the number of further installations in the municipality is reduced by $1.26 \mathrm{PV}$ systems. For $K=3$, the installation history of the first two systems may differ between treatment municipalities. Again, installations farther in the past imply a weaker social effect. For $K=4$, the point estimates for the distance interactions are all negative. While these effects are all significantly negative on the number of installations, they are not all statistically significant for the probability of installations. Still, overall, the effect of distance on the social effect is negative, and temporally more concentrated installations (smaller $d_{k}$ ) affect others more.

Result 6. The social effect is stronger with temporally more concentrated installations, i.e., if there are more installations in the recent past rather than the distant past.

\section{Robustness}

\subsection{Alternative specifications and robustness checks}

In this section we present the treatment effect estimates using different specifications, parameters, or sets of observations. The biggest concern with any matching approach is whether it really matches treatment municipalities with comparable control municipalities to obtain an estimate of the counterfactual.

Exclude municipalities with pre-EEG installations. Our first robustness check directly addresses the concern that the matching does not account for all relevant variables. In the EEG data, we observe PV systems that have been installed before the EEG went into force and thus before the EEG guaranteed feed-in tariffs to PV system owners. ${ }^{11}$ In other

\footnotetext{
${ }^{11}$ The EEG allowed older systems to be subsidized from 2000 onwards only if these systems had a major refit after the EEG went into force, i.e., only with substantial investment due to the EEG. The pre-EEG
} 
Table 5: ATT using different specifications and parameters

\begin{tabular}{lccccc}
\hline Description & ProbInstall & NumInstall & NumInstall per 1000 & $\mathrm{~N}$ & Clusters \\
\hline 1. Main matching & $0.118^{* * *}$ & $0.800^{* * *}$ & $0.587^{* * *}$ & 22284 & 10712 \\
model & $(0.007)$ & $(0.065)$ & $(0.040)$ & & \\
2. Exclude obs with & $0.130^{* * *}$ & $0.662^{* * *}$ & $0.650^{* * *}$ & 17842 & 8557 \\
pre-EEG solar panels $^{a}$ & $(0.008)$ & $(0.056)$ & $(0.050)$ & & \\
3. Fixed effects on & $0.225^{* * *}$ & $1.179^{* * *}$ & $0.692^{* * *}$ & 20832 & 10312 \\
district level $^{b}$ & $(0.007)$ & $(0.041)$ & $(0.044)$ & & \\
4. Exclude multiple & $0.078^{* * *}$ & $0.513^{* * *}$ & $0.144^{* * *}$ & 21902 & 10666 \\
panels on same street $^{c *}$ & $(0.007)$ & $(0.040)$ & $(0.029)$ & & \\
5. Without & $0.157^{* * *}$ & $0.659^{* * *}$ & $0.517^{* * *}$ & 12898 & 9862 \\
replacement $^{d *}$ & $(0.008)$ & $(0.065)$ & $(0.034)$ & & \\
6. Pooled propensity & $0.137^{* * *}$ & $0.798^{* * *}$ & $0.636^{* * *}$ & 22306 & 10711 \\
score estimation $^{e}$ & $(0.007)$ & $(0.054)$ & $(0.040)$ & & \\
7. Match only within & $0.125^{* * *}$ & $0.819^{* * *}$ & $0.602^{* * *}$ & 20782 & 10437 \\
state $^{f}$ & $(0.008)$ & $(0.070)$ & $(0.043)$ & & \\
\hline
\end{tabular}

Note: The table reports the average treatment effect on the treated on three outcome variables, the probability, number, and number (per 1000 inhabitants) of solar panel installations within one year using different specifications and parameters in the matching procedure.

a All municipalities with solar panels installed before inactment of the EEG are dropped from the sample before matching.

${ }^{b}$ Fixed effects on district rather than state level in the propensity score estimation.

${ }^{c}$ Count only the first panel if several panels are installed on the same street.

${ }^{d}$ Main matching model except without replacement of control municipalities.

${ }^{e}$ One propensity score regression over all years with year fixed effects.

$f$ Match only with municipalities in the same state.

$* * *$ Significant at the $1 \%$ level; ${ }^{* *}$ significant at the $5 \%$ level; ${ }^{*}$ significant at the $10 \%$ level.

words, we observe past outcomes, which allows us to see whether our matching approach is able to predict current outcomes correctly. Municipalities with pre-EEG installations are very likely to also install under the EEG, for example because they are bigger, solar radiation is stronger, or other factors we might not have considered are more favorable. Consequently, if we do not account for unobserved differences that favor treatment municipalities, then we should underestimate counterfactual outcomes for these municipalities with pre-EEG installations in particular, and we should obtain a considerably smaller treatment effect when excluding these municipalities.

Specification 2 in Table 5 reports the ATTs once we exclude all of the municipalities with pre-EEG installations. Comparing with the main specification that includes those, the estimated treatment effects barely change, even though the sample is reduced by about $20 \%$. In other words, we exclude $20 \%$ of the observations which - based on past outcomes-

installations data is thus not exhaustive like the post-EEG installations data, since not all pre-EEG PV owners chose to modernize, but it is still very informative about a municipality's propensity to install PV systems. 
are most prone to install PV systems, and yet our estimates barely change. This result suggests that our matching procedure captures all important factors determining treatment and outcomes, and the results are not driven by selection on unobservables.

Fixed effects on district level. Another way to address the concern of unobserved differences is by using fixed effects on a finer geographical level. In the main specification we use state (Länder, NUTS-1 region) fixed effects, specification 3 in Table 5 uses district (Kreis, NUTS-3 region) level fixed effects. ${ }^{12}$ In 2000, Germany had 440 districts ${ }^{13}$ compared to 16 states, increasing the number of fixed effects considerably. Hence, if there are relevant factors at the district level that are not picked up in our main matching procedure, then we should observe different treatment effects once we use these fixed effects on this finer geographical level. However, the table shows that the treatment effect estimates increase, if anything.

Exclude multiple installations on the same street. There might be the problem that some households install multiple systems. If a household installs several systems in the same year in the same municipality, then it looks as if these new systems are the result of social interaction, whereas it is actually the same decision maker installing more systems.

Unfortunately we do not observe the identity of the installers in the anonymized data. However, since we observe the street and zip code where each system was installed, we can run robustness tests on the basis of these address information. More specifically, we exclude all PV systems but the first that are installed on the same street. This radical approach will also exclude systems genuinely installed due to social interaction (e.g., neighbor influenced by peer effects), hence we obtain conservative treatment effect estimates, but we can be sure that all multiples installed by the same household at the same address are removed. Thus, if we still find a positive treatment effect, then it cannot be explained by the same households installing multiple PV systems. Specification 4 in Table 5 reports the results of this robustness check. Although the estimated ATTs are noticeably smaller, the effects are still positive on all outcome measures. Thus, even if we can reasonably exclude the possibility of the same individuals installing multiple systems, the effects remain economically and statistically significant.

Without replacement. We want to determine the impact of allowing replacement of control municipalities on the estimates, which can give single control municipalities a lot of weight. Specification 5 in Table 5 matches with the same ambitious caliper as the main model, but does not allow the same untreated municipality to be matched with different treatment municipalities. We lose almost half of the sample by not allowing replacement, but

\footnotetext{
${ }^{12}$ We cannot use fixed effects on an even finer level, e.g., on municipality level, because the fixed effect dummies would perfectly predict the outcomes of the municipality. We already lose some observations by using district fixed effects in specification 3, because there is no variation in treatment for some districts in some years. The matching approach relies on the $x$-vector used for matching not perfectly predicting treatment, otherwise one cannot find municipalities with similar propensity scores that are treated and untreated.

${ }^{13}$ More precisely, 323 districts and 117 bigger cities that constitute their own district (kreisfreie Städte).
} 
the resulting ATT estimates are very similar to the main model. Consequently, the results we find are not driven by a few control municipalities that have been matched repeatedly in the main model.

Pooled propensity score estimation. We replace the year specific propensity score regressions with a single regression spanning all years. If there are problems for example due to a small sample size in later years, then we should remove those in this robustness check. Specification 6 in Table 5 gives the results, and they are very close to the main model. ${ }^{14}$

Match only within state. Finally, based on our main matching model, we impose the hard constraint that municipalities can only be matched with municipalities in the same state. This hard constraint means we lose some observations if no good match exists in the same state that fulfills our caliper, but it also means that the matched pairs tend to be geographically closer. The estimates are very close to those of the main matching model.

In conclusion, reasonable robustness checks confirm the magnitude of the social effects obtained in the main specification. In fact, we have not been able to find a single specification where we did not get significantly positive effects on PV installations due to social interaction. Thus, the matching method employed in this paper is very robust to changes in the specification or sample.

\subsection{Sensitivity analysis}

While the identifying assumption in matching is not testable, several authors have developed tests that allow us to assess how sensitive our matching specification is to "hidden bias," i.e., to unobservable factors that affect both treatment status and outcomes. These tests do not tell us whether such hidden biases exist, only whether the treatment effect estimate is sensitive to a hypothetical hidden bias of a given magnitude. Thus, the tests postulate the existence of a hidden bias and ask how large such a hidden bias can be without affecting our conclusions.

The tests are based on bounds developed by Rosenbaum (2002) and implemented by for example Becker and Caliendo (2007) and DiPrete and Gangl (2004). The basic idea is to assume there exists an unobserved variable that affects the probability of participation for municipality $i$ at $t$. Rosenbaum (2002) showed that the odds ratio of a matched municipality pair $i$ and $j$ can be bounded depending on the strength of the simulated bias $\Gamma$. At $\Gamma=1$, there is no hidden bias. The tests then amount to increasing $\Gamma$ step by step, which gives the treatment municipality a stronger hidden bias and allows us to test whether the treatment

\footnotetext{
${ }^{14}$ The Abadie and Imbens (2016) standard errors for the matching estimator make several assumptions that are not fulfilled in our main matching procedure, such as independence of observations and a single propensity score estimation. Still, for comparison we compute the Abadie and Imbens (2016) standard errors here, as this pooled propensity score estimation is closer to their setup with the latter assumption being fulfilled. The standard errors are $0.010,0.053,0.064$ for the three outcome variables, slightly larger but very close to the clustered standard errors we use; this different way of computing SEs does not change our conclusions at any conventional significance levels. Details on the computation are available upon request.
} 
Table 6: Sensitivity to unobserved heterogeneity for binary outcome (left) and count outcome (right)

\begin{tabular}{ccccccc}
\hline$\Gamma$ & $Q^{+}$ & $p^{+}$ & & $\Gamma$ & $p^{+}$ \\
\cline { 1 - 2 } \cline { 6 - 7 } 1.00 & 17.906 & 0.000 & & 1.00 & 0.000 \\
1.10 & 15.221 & 0.000 & & 1.10 & 0.000 \\
1.20 & 12.777 & 0.000 & & 1.20 & 0.000 \\
1.30 & 10.534 & 0.000 & & 1.30 & 0.000 \\
1.40 & 8.462 & 0.000 & & 1.40 & 0.000 \\
1.50 & 6.535 & 0.000 & & 1.50 & 0.000 \\
1.60 & 4.735 & 0.000 & & 1.60 & 0.000 \\
1.70 & 3.045 & 0.001 & & 1.70 & 0.000 \\
1.80 & 1.452 & 0.073 & & 1.80 & 0.003 \\
1.90 & 0.018 & 0.493 & & 1.90 & 0.113 \\
\cline { 1 - 2 } \cline { 5 - 6 } & & & &
\end{tabular}

effect would still be positive with the hidden bias.

Since we find positive treatment effects throughout, we focus on simulating a positive hidden bias $(\Gamma>1)$ so that the treatment municipality has a higher probability of treatment than its matched counterpart. Moreover, we use the matched dataset obtained without replacement for the tests, since our non-standard matching approach with replacement does not fit the assumptions of the tests. First, we conduct the test of Becker and Caliendo (2007) for the outcome indicator whether additional systems have been installed in the year after treatment. Table 6 , left side, reports the test statistic $Q^{+}$(given positive hidden bias) and the corresponding $\mathrm{p}$-value $p^{+}$for the null hypothesis of no treatment effect given the simulated unobserved heterogeneity.

The critical value for the $1 \%$ significance level is in $\Gamma \in(1.7,1.75)$ and for the $5 \%$ level it is in $\Gamma \in(1.75,1.8)$. Thus, our conclusion that social effects increase the probability of installations holds even if there were a hidden bias that increases the odds ratio of the matched treatment and control municipalities from 1.0 to 1.7.

Second, we conduct the test implemented by DiPrete and Gangl (2004) for the count data outcome (number of PV installations within the year). The test also uses the Rosenbaum bounds and conducts a Wilcoxon signed-rank test on the differences between the matched pairs. Table 6 , right side, reports the p-values for the null hypothesis of no treatment effect in the case with positive hidden bias. The results are even more robust than in the binary case with significant differences at the $1 \%$ level even for $\Gamma=1.8$. The critical value for the $1 \%$ significance level is in $\Gamma \in(1.8,1.85)$ and for the $5 \%$ level it is in $\Gamma \in(1.85,1.9)$. Thus, overall, the hidden bias would have to be unusually strong for our conclusions to be wrong. 


\section{$6 \quad$ Policy implications}

For the EEG regulation, social interactions that affect the spatial allocation of PV systems have policy implications along at least three dimensions. First, the EEG regulation offers a compensation rate above competitive market levels. As such, it pays for households to install PV systems in areas where it would not pay in a competitive setting, for example because of insufficient solar radiation potential in northern Germany. ${ }^{15}$ Social interaction can exacerbate these inefficiencies if it becomes fashionable to install PV systems in such areas. In line with this, we find that social effects increase participation in the program and uptake of the subsidy even in the municipalities with the lowest solar potential (see section 4.2 and in particular Figure 3). A shift from the posted price mechanism that the EEG currently is to a more competition-based mechanism such as auctions could lead to more PV systems in areas where they can produce the most energy or where energy is needed most, so that installations due to social interaction in inefficient areas are less of a problem. Potentially, the existing tariffs could be changed to react to local characteristics, but this requires a lot of knowledge and timely reaction by the regulator-something that is not necessary with the auction.

In the latest revision of the law (effective since 2017), steps have been taken to employ auctions as allocation mechanisms. ${ }^{16}$ The first regular auctions conducted so far suggest that reductions in remunerations are possible. For the first round of bidding in February 2017, the average accepted bid was 6.58 ct/kWh (Federal Network Agency, 2017). The latest possible fixed remuneration rate was $8.93 \mathrm{ct} / \mathrm{kWh}$.

Second, social interaction may lead to local clustering of installations and may therefore cause local excess power supply. Currently, the regulation does not have any safeguards against excessive installations in areas where more power production is not needed. Thus, the energy that is produced in these areas is either wasted or has to be transported off, possibly requiring investments in the long-range power transmission grid as the share of renewable energy increases. These transmission lines are costly, imply higher energy loss, and are often met with a strong 'not in my backyard'-type of local opposition, citing the significant change in the landscape among other things (e.g., WSJ, 2009; FT, 2015). Consequently, the EEG and other policies whose success and efficiency depends on a spatial distribution should add constraints. For example, the EEG may deny subsidies in areas where a lot of systems already exist or where an excess power supply is common. The funds are then better used to install PV systems where power is in short supply (e.g., close to major cities or industrial areas). Another possible disadvantage of a strong spatial concen-

\footnotetext{
${ }^{15}$ See Figure 1. According to the data, relocating a system from the area with minimal to the area with maximal solar energy potential within Germany gives a theoretical energy production increase of about $33 \%$ with the same system (i.e., for the same cost). For wind energy potential, differences within Germany are even larger.

${ }^{16}$ The auctions so far are limited to large systems. Also note that already in 2015 and 2016 pilot-auctions were conducted to test and evaluate different design proposals
} 
tration of PV systems is that it makes diversification against weather shocks less effective. Currently, the policy does not account for local power grid characteristics or concentration.

Third, the large social effects we find - which increase the number of installations by about a half - can in part explain why the participation rate and the associated costs are very large for the EEG program. A common view is that a lot of households joined the program after solar panel costs dropped and the regulator did not adjust compensation rates quickly enough, which made participation very attractive. But our findings show these cost decreases are not the only reason. ${ }^{17}$ Given that positive social effects can lead to considerably more installations compared to a model based on isolated decisions, the regulation could add safeguards against an unexpectedly large uptake of the feed-in tariffs to protect consumers from the 20 year payment obligations, and also to make the expansion of renewable energy more predictable. It may be surprising that such an obvious recommendation is necessary, but even now the EEG does not have hard constraints in the sense that it stops subsidizing at a threshold capacity or number of PV installations. Only some soft constraints have been added in the last few years, for example that the compensation rate declines as more systems are installed (see section 2.1). Controlling the number of new installations is also important because there is evidence from the US that the carbon emissions offset by each new installation decreases as the stock increases (Novan, 2015).

In summary, while the disincentives induced by minimum prices are well known, our results show these effects may be even more pronounced due to social interactions in the case of the EEG. Thus, measures working towards a more competitive allocation mechanism might be even more beneficial than previously thought.

\section{Conclusion}

In this paper, we analyzed one of the largest renewable energy support programs, the German EEG regulation. This regulation allows households and companies to install PV systems and receive a minimum price for each $\mathrm{kWh}$ that is produced, which is set above competitive market prices. We asked whether the decision to become a producer and install a system on one's roof is influenced by others in the area, and whether this has consequences for allocative efficiency in energy production.

Our results suggest that social interaction plays a significant role in explaining if and where PV systems are installed. We estimate that social effects, i.e., the effect of having at least one other PV system in the municipality, increase the probability and number of new installations considerably by up to $50 \%$. These large estimates can explain part of the spatial clustering of PV systems that we observe in Germany. In the context of energy,

\footnotetext{
${ }^{17}$ Recall that we compare outcomes in control and treatment municipalities in the same time interval, where panel costs were identical. Note also that there could be an interaction between social effects and price decreases, so that word spreads more quickly if a price decrease made participation more attractive.
} 
such clustering is crucial to recognize and understand because energy cannot be stored or transported without cost. Moreover, we find that social effects account for installations even at minimal solar radiation levels, which suggests that social interaction can exacerbate the adverse effects of the inefficient policy design. Thus, social effects appear to add a secondary inefficiency to minimum prices that has not been considered before. We derive several policy recommendations based on our findings. In particular, a multi-unit auction that induces competition between potential producers could lower compensation rates and ensure production in areas with the largest solar potential or power demand. The lower competitive compensation rates should also remove the basis for the inefficient installations due to solar interaction.

In future work, it would be interesting to directly investigate the allocative efficiency of the EEG remuneration scheme with data on spatial demand and supply in the power grid, and quantify the costs of offsetting carbon emissions. Previous program evaluations found that subsidies for renewables or energy-efficient consumption goods can reduce emissions, but are rather costly (e.g., Cullen, 2013; Davis et al., 2014). It is also important to investigate the exact social channels that drive the PV expansion further. Finally, our results imply the theoretical question how social interaction should be included in the design of a policy. 'Mechanism design with social interactions', i.e., mechanism design which recognizes that decisions are not made in isolation, may therefore be a fruitful tool for these kinds of policies.

\section{Acknowledgments}

We are grateful to two anonymous referees and Richard Tol (the editor) whose suggestions improved the paper, and thank Hans Peter Grüner, Mario Meier, Kathleen Nosal, Andreas Peichl, Johannes Rode, Sebastian Siegloch, Ulrich Wagner, seminar participants at the University of Mannheim, ZEW, and the University of Essex for helpful comments. We also thank Sebastian Siegloch and Max Loeffler for providing us with German municipality structure data. This research was supported by the German Research Foundation (DFG) via SFB 884.

\section{References}

Abadie, A. And G. W. Imbens (2016): "Matching on the estimated propensity score," Econometrica, 84, 781-807.

Abadie, A. And J. Spiess (2016): "Robust Post-Matching Inference," mimeo.

Becker, G. S. And K. M. Murphy (2000): Social economics. Market behavior in a social environment., Harvard University Press. 
Becker, S. O. And M. CALiendo (2007): "Sensitivity analysis for average treatment effects," Stata Journal, 7, 71-83.

Blundell, R. And M. C. Dias (2009): "Alternative approaches to evaluation in empirical microeconomics," Journal of Human Resources, 44, 565-640.

BMJ (2000): "Gesetz fuer den Vorrang Erneuerbarer Energien (Erneuerbare-Energien-Gesetz EEG) sowie zur Aenderung des Energiewirtschaftsgesetzes und des Mineraloelsteuergesetzes," Federal Law Gazette (Bundesgesetzblatt) 2004, No. 40, published in Bonn on 31 March, 2000.

BMWI (2016): "Zeitreihen zur Entwicklung der erneuerbaren Energien in Deutschland," http://www.erneuerbare-energien.de/EE/Redaktion/DE/Downloads/ zeitreihen-zur-entwicklung-der-erneuerbaren-energien-in-deutschland-1990-2015. pdf?_-_blob=publicationFile\&v=6, accessed 19/4/2016, Federal Ministry for Economic Affairs and Energy.

(2017): "EEG in Zahlen: Verguetungen, Differenzkosten und EEG-Umlage 2000 bis 2018," https://www.erneuerbare-energien.de/EE/Redaktion/DE/Downloads/ eeg-in-zahlen-pdf.pdf\%3F__blob\%3DpublicationFile, accessed 31/5/2018, Federal Ministry for Economic Affairs and Energy.

Böhringer, C., A. Cuntz, D. Harhoff, And E. Asane-Otoo (2017): "The impact of the German feed-in tariff scheme on innovation: Evidence based on patent filings in renewable energy technologies," Energy Economics, 67, 545-553.

Bollinger, B. And K. Gillingham (2012): "Peer effects in the diffusion of solar photovoltaic panels," Marketing Science, 31, 900-912.

Couture, T. and Y. Gagnon (2010): "An analysis of feed-in tariff remuneration models: Implications for renewable energy investment," Energy Policy, 38, 955-965.

Cullen, J. (2013): "Measuring the environmental benefits of wind-generated electricity," American Economic Journal: Economic Policy, 5, 107-133.

Davis, L. W., A. Fuchs, And P. Gertler (2014): "Cash for coolers: evaluating a large-scale appliance replacement program in Mexico," American Economic Journal: Economic Policy, 6, 207-238.

Dijkgraaf, E., T. P. van Dorp, and E. Maasland (2018): "On the Effectiveness of Feed-in Tariffs in the Development of Solar Photovoltaics." Energy Journal, 39, 81-99.

DiPrete, T. A. And M. Gangl (2004): "Assessing bias in the estimation of causal effects: Rosenbaum bounds on matching estimators and instrumental variables estimation with imperfect instruments," Sociological Methodology, 34, 271-310.

Federal Network Agency (2017): "Public announcement of winning bids," https://www. bundesnetzagentur.de/DE/Sachgebiete/ElektrizitaetundGas/ 
Unternehmen_Institutionen/ErneuerbareEnergien/Ausschreibungen/Solaranlagen/ BeendeteAusschreibungen/Gebotstermin_01_02_2017/gebotstermin_01_02_17_node. html, accessed 6/27/2017.

Frondel, M., N. Ritter, C. M. Schmidt, And C. Vance (2010): "Economic impacts from the promotion of renewable energy technologies: The German experience," Energy Policy, 38, 4048-4056.

FT (2015): "Compromise and opposition on road to Germany's renewable energy," http://www . ft.com/intl/cms/s/2/6a254194-47e9-11e5-af2f-4d6e0e5eda22.html.

Glaeser, E. L., B. I. Sacerdote, And J. A. Scheinkman (2003): "The social multiplier," Journal of the European Economic Association, 1, 345-353.

Graziano, M. and K. Gillingham (2015): "Spatial Patterns of Solar Photovoltaic System Adoption : The Influence of Neighbors and the Built Environment," Journal of Economic Geography, 15, 815-839.

JACKson, M. O. (2016): "The Past and Future of Network Analysis in Economics," in The Oxford Handbook of the Economics of Networks, ed. by Y. Bramoullé, A. Galeotti, and B. Rogers, Oxford University Press.

Jacobsson, S. And V. LAuber (2006): "The politics and policy of energy system transformation - explaining the German diffusion of renewable energy technology," Energy Policy, 34, $256-276$.

Jaffe, A. B., R. G. Newell, And R. N. Stavins (2005): "A tale of two market failures: Technology and environmental policy," Ecological Economics, 54, 164-174.

Kalkuhl, M., O. Edenhofer, and K. Lessmann (2013): "Renewable energy subsidies: Second-best policy or fatal aberration for mitigation?" Resource and Energy Economics, 35, $217-234$.

Novan, K. (2015): "Valuing the wind: renewable energy policies and air pollution avoided," American Economic Journal: Economic Policy, 7, 291-326.

RIchter, L. (2014): "Social Effects in the Diffusion of Solar Photovoltaic Technology in the UK," mimeo.

Rode, J. ANd S. Müller (2016): "Spatio-Temporal Variation in Peer Effects - The Case of Rooftop Photovoltaic Systems in Germany," Working Paper.

Rode, J. And A. Weber (2016): "Does localized imitation drive technology adoption? A case study on rooftop photovoltaic systems in Germany," Journal of Environmental Economics and Management, 78, 38-48.

Rosenbaum, P. R. (2002): "Observational studies," in Observational Studies, Springer. 
Rosenbaum, P. R. And D. B. Rubin (1983): "The central role of the propensity score in observational studies for causal effects," Biometrika, 70, 41-55.

Schwarz, A. (2014): "Die Förderung der Stromerzeugung aus erneuerbaren Energien in Deutschland," Wissenschaftliche Dienste des Deutschen Bundestags (German Parliament).

SiAnESI, B. (2004): "An evaluation of the Swedish system of active labor market programs in the 1990s," Review of Economics and Statistics, 86, 133-155.

WSJ (2009): "Renewable Energy, Meet the New Nimbys," http://www.wsj.com/articles/ SB125201834987684787.

Young, P. H. (2009): "Innovation Diffusion in Heterogeneous Populations: Contagion, Social Influence, and Social Learning," American Economic Review, 99, 1899-1924. 